\title{
ECONOMIA BRASILEIRA NO INÍCIO DO SÉCULO XXI: DESACELERAÇÃO, CRISE E DESINDUSTRIALIZAÇÃO $(2000-2017)^{*}$
}

\author{
Recebido: 16 de agosto de 2018 - Aprovado: 1 de novembro de 2018 \\ https://doi.org/10.22395/seec.v22n50a6 \\ Daniel Pereira Sampaio*
}

\section{RESUMO}

O objetivo do artigo é discutir a hipótese de desindustrialização absoluta no Brasil, principalmente a partir da segunda década do século XXI, quando o país entrou no ciclo da desaceleração e, posteriormente, da crise econômica. Para atingir tais objetivos, a trajetória da economia brasileira é organizada em ciclos: início de reversão (1999-2002), recuperação do crescimento (2003-2006), aceleração do crescimento (2007-2010), desaceleração (2011-2014), crise econômica (2015-2017). São utilizados dados do Produto Interno Bruto (PIB), produção industrial, contas externas e empregos. Os resultados apontam que o país está a caminho da desindustrialização absoluta desde o ciclo da desaceleração, tendo em vista que se observa queda da produção industrial e baixo dinamismo do PIB. Os setores de bens de capital e bens de consumo duráveis são os mais afetados, com reduções expressivas, em face da grande recessão.

\section{PALAVRAS-CHAVE}

Economia brasileira contemporânea; crescimento e flutuações; desindustrialização; Brasil.

\section{CLASSIFICAÇÃO JEL}

O14, O54, L60

\section{CONTEÚDO}

Introdução; 1. Crescimento e ciclo na economia brasileira no início do século XXI; 2. Desindustrialização no Brasil: agravamento no quadro de desaceleração e crise; 3. Conclusões; Bibliografia.

\footnotetext{
Este artigo é uma investigação realizada pelo "Grupo de Estudos em Desenvolvimento, Economia e Território", registrado no Diretório de Grupos do $\mathrm{CNPq} / \mathrm{Brasil}$, referente ao projeto de pesquisa "Desindustrialização e impactos regionais no Brasil (1985-2015)", registrado na PRPPG/UFES, com vigência de março/2017 até março/2019.

. Economista, Universidade Federal do Espírito Santo, Vitória, Brasil. Mestre em Desenvolvimento Econômico, Universidade Estadual de Campinas, Campinas, Brasil. Doutor em Desenvolvimento Econômico, Universidade Estadual de Campinas, Campinas, Brasil. Professor do Departamento de Economia, Universidade Federal do Espírito Santo, Vitória, Brasil. E-mail: daniel.sampaio@ufes.br
} 


\title{
ECONOMÍA BRASILEÑA EN EL INICIO DEL SIGLOXXI: DESACELERACIÓN, CRISIS Y DESINDUSTRIALIZACIÓN (2000-2017)
}

\section{RESUMO}

El objetivo del artículo es discutir la hipótesis de desindustrialización absoluta en Brasil, principalmente a partir de la segunda década del siglo XXI, cuando el país entró en el ciclo de la desaceleración y, posteriormente, de la crisis económica. Para alcanzar dichos objetivos, la trayectoria de la economía brasileña está organizada en ciclos: inicio de reversión (1999-2002); recuperación del crecimiento (2003-2006); aceleración del crecimiento (2007-2010); desaceleración (2011-2014) y crisis económica (2015-2017). Se utilizan datos del Producto Interno Bruto (PIB), producción industrial, cuentas externas y empleos. Los resultados indican que el país está en camino de la desindustrialización absoluta desde el ciclo de la desaceleración, teniendo en cuenta que se observa caída de la producción industrial y bajo dinamismo del PIB. Los sectores de bienes de capital y bienes de consumo durables son los más afectados, con reducciones expresivas, dada la gran recesión.

\section{PALABRAS CLAVE}

Economía brasileña contemporánea; crecimiento e fluctuaciones; desindustrialización; Brasil.

\section{CLASSIFICACIÓN JEL}

O14, O54, L60

\section{CONTENIDO}

Introducción; 1. Crecimiento y ciclo en la economía brasileña en el inicio del siglo XXI; 2. Desindustrialización en Brasil: agravamiento en el cuadro de desaceleración y crisis; 3. Conclusiones; Bibliografía.

\section{BRAZILIAN ECONOMY AT THE BEGINNING OF THE $21^{\text {ST }}$ CENTURY: DECELERATION, CRISIS, AND DE-INDUSTRIALIZATION (2000-2017)}

\begin{abstract}
This article aims at discussing the hypothesis of absolute de-industrialization in Brazil, mainly from the second decade of the 21 st century, when the country entered a cycle of deceleration and, subsequently, an economic crisis. In order to achieve these goals, the trajectory of the Brazilian economy was organized in cycles: the beginning of reversal (1999-2002), growth recovery (20032006), growth acceleration (2007-2010), slowdown (2011-2014) and economic crisis (2015-2017). We used data from Gross Domestic Product (GDP), industrial production, external accounts, and jobs. The results indicate that the country is on its way to absolute de-industrialization since the cycle of deceleration, considering that it is possible to observe a decline in industrial production and low dynamism of GDP. The sectors of capital goods and durable consumer goods are the most affected, with dramatic reductions, in the face of the great recession.
\end{abstract}

\section{KEYWORDS}

Contemporary Brazilian economy; growth and fluctuations; de-industrialization; Brazil.

\section{JEL CLASSIFICATION}

O14, O54, L60

\section{CONTENT}

Introduction 1. Growth and cycle in the Brazilian economy at the beginning of the 21 st century; 2. De-industrialization in Brazil: worsening in the framework of deceleration and crisis; 3. Conclusions; Bibliography. 


\section{INTRODUÇÃO}

O debate sobre as possibilidades, as origens e as causas da desindustrialização brasileira tem motivado intensas discussões desde o início dos anos 2000. A desindustrialização pode ser entendida, segundo a (2003, p. VII) e Tregenna (2009, p. 436-438), em suma, como a redução, no longo prazo, do valor adicionado do setor manufatureiro em relação ao valor adicionado total (grau de industrialização). Trata-se, portanto, de um fenômeno relativo, que indica uma mudança na estrutura do PIB e na dinâmica econômica de determinado país. Ela tem distintos impactos sobre o desenvolvimento no tempo e no espaço, e é subproduto do processo de financeirização da riqueza capitalista, por meio de suas políticas de corte neoliberal, e avanços na internacionalização dos processos produtivos.

Nos países de industrialização avançada, esse processo teve início no final da década de 1960 e pode ser explicado devido ao desenvolvimento de maturidade do setor industrial, que se desdobrou em diversificação do setor de serviços, sobretudo aqueles ligados a um maior valor agregado, e seguiu movimentos de terceirização e subcontratação, aumento da produtividade do setor manufatureiro e aumento da intensidade tecnológica das exportações, em decorrência da globalização produtiva, como apontou Singh (1977, p. 114) e Rowthorn e Coutts (2004, p. 767-771).

Em países de capitalismo tardio, esse processo tem suas origens na década de 1980, mas consolida-se na década de 1990, com as políticas do Consenso de Washington. Nesse período, a indústria de transformação desses países não se encontrava madura. Entre os condicionantes externos, cabe destaque à emergência das políticas de corte neoliberal discutida, por exemplo, em Paulani (1999, p. 121); a financeirização da riqueza capitalista em Braga (1993, p. 39-41); a reorganização da grande empresa transnacional, na forma da fragmentação da produção global por meio das cadeias globais de valor (CGV), discutido por Carneiro (2017, p. 88-96); bem como à mudança do paradigma tecnológico, via terceira revolução industrial, estudada por Coutinho (1992, p. 71-86). Os condicionantes internos remontam à crise da dívida externa dos anos 1980, aos processos de abertura comercial e financeira dos anos 1990 e ao Plano Real (a partir de 1994), que consolidou o projeto liberal no Brasil.

A controvérsia sobre o debate da desindustrialização no Brasil ganhou maior destaque após a publicação da Unctad (2003, p. VII), que afirmou que o Brasil passava por uma desindustrialização relativa e precoce em decorrência da quebra de elos em cadeias produtivas. Após mais de uma década da publicação desse documento o debate se aprofundou, tanto em aspectos teóricos e metodológicos quanto históricos. De acordo com Sampaio (2015, p. 84), a desindustrialização 
brasileira pode ser compreendida, por meio de uma abordagem que contempla as seguintes dimensões: i) aumento do gap tecnológico; ii) quebra de elos em cadeias produtivas - com redução do conteúdo nacional; iii) substituição do produto final nacional pelo importado, e iv) fechamento de unidades locais industriais, com efeitos setoriais e regionais diferenciados.

As três primeiras dimensões têm relação direta com a desindustrialização relativa, na medida em que é compatível com taxas de crescimento positivas na manufatura doméstica, mas em baixo patamar e com redução da diversificação do parque industrial ${ }^{1}$. Trata-se de alterações nas articulações macroeconômicas, microeconômicas e territoriais erigidas na construção do sistema econômico nacional, que ocorreu no período de industrialização por substituição de importações (ISI), entre 1930 e 1980 (Furtado, 1992, p. 32).

A desindustrialização absoluta, por sua vez, está relacionada com a redução em valores reais e também com a diminuição da produção física e do emprego da indústria de transformação em determinado tempo e espaço econômico no médio e no longo prazo. Ou seja, implica em perda de produção física, aumento de capacidade ociosa e redução do número de empregos industriais na economia. Trata-se da forma mais grave de desindustrialização, na medida em que a perda de capacidade produtiva e do número de empregados no setor manufatureiro implicam em elevação substantiva da segregação social² e dependência externa.

O objetivo deste artigo é discutir a hipótese de que o Brasil está passando por um período de desindustrialização absoluta desde o início da segunda década do século XXI. Entende-se por desindustrialização absoluta a trajetória de médio e longo prazo de diminuição da produção e emprego da manufatura. Para atingir tais objetivos, o artigo está divido em duas seções. Na primeira, discutese o crescimento e ciclo na economia brasileira no século XXI, e, na segunda, o processo de desindustrialização no Brasil, com ênfase no período pós-2010, quando se confirma a hipótese de desindustrialização absoluta. Por fim, seguem as considerações finais.

Em relação a certas regiões brasileiras já são observados processos de desindustrialização absoluta. Por exemplo, em um estudo da região metropolitana do Rio de Janeiro, Silva (2009, p. 152-153) argumentou que "a desindustrialização metropolitana

\footnotetext{
${ }^{1}$ Que é um condicionante interno do processo de reprimarização da pauta de exportações brasileiras. O aumento da demanda internacional de commodities agrícolas e mineiras, influenciado pelo efeito China que, de acordo com Gonçalves e Pinto (2016, p. 467-475), é um dos condicionantes externos.

2 O diretor Michael Moore demostra os efeitos do fechamento de fábricas automobilísticas na década de 1990, ou seja, uma desindustrialização absoluta, em Flint, nos Estados Unidos, e os impactos sobre a renda, emprego e segregação urbana no filme Roger E Eu.
} 
foi, evidentemente, determinada pelo resultado carioca", pois apresentou queda do número de unidades locais industriais e população ocupada entre 1996 e 2006; para o caso de Santo André, município da região metropolitana de São Paulo, Ferreira (2015, p. 20-21) demonstrou a queda do emprego industrial na região e uma listagem com fechamento de unidades locais industriais cujos terrenos são atualmente, por exemplo, condomínios, shopping centers, entre outros; em relação ao estado de Santa Catarina, Cário (2012, p. 21-22) demonstra que há desindustrialização absoluta, entendida como redução do emprego e produção industrial, de forma setorialmente determinada, como em Madeira e Móveis.

Ao considerar alguns estudos, pode-se observar ao menos duas abordagens metodológicas para a compreensão da desindustrialização absoluta: a partir dos agregados de uma região e das dinâmicas setoriais de uma região em determinado momento do tempo. A partir desses estudos regionais e setoriais, é possível dizer que a economia brasileira se encontra num processo de desindustrialização absoluta?

Para alcançar tais objetivos, será discutido o contexto no qual a economia brasileira se insere e será demonstrada a perda de dinamismo econômico, principalmente da manufatura, o que denota uma desindustrialização relativa desde a segunda metade dos anos 1980 e sua continuidade no breve século XXI. Após, serão discutidos dados de produção (Contas Nacionais, PIM-PF, Utilização da Capacidade Instalada) e de emprego formal (RAIS) para o período de 2011 a 2017, o que demonstra o agravamento do problema industrial brasileiro no médio prazo, com tendência à queda em termos absolutos da produção física e emprego formal. A hipótese deste artigo é de que a desindustrialização brasileira, desde 2011, está a caminho de se manifestar como absoluta, haja vista a persistência de taxas médias negativas de variação da produção e do emprego industrial.

\section{CRESCIMENTO E CICLO NA ECONOMIA BRASILEIRA NO INÍCIO DO SÉCULO XXI}

Desde a mudança no centro dinâmico, conforme Furtado (2007, p. 274-285), no início da década de 1930, a economia brasileira começou seu processo de industrialização, no qual foram constituídas as bases para o processo endógeno de acumulação e reprodução do capital, com origens no complexo cafeeiro capitalista do oeste paulista. A industrialização ocorreu, ainda que houvesse limites para a plena constituição das forças produtivas, em termos de concentração de capital, financiamento externo, financiamento do setor público e condições técnicas, por isso restringida, segundo Mello (1982, p. 110). Entre os anos 1950 e 1980, a economia brasileira cresceu a uma taxa média de 7 \% ao ano e consolidou a transição da economia tipicamente 
primário-exportadora para a urbano-industrial, alavancada por sucessivas políticas de diversificação produtiva, tais como o Plano de Metas e o II Plano Nacional de Desenvolvimento (PND), que resultaram na fase da industrialização pesada.

No final da década de 1970, o parque produtivo nacional encontrava-se regionalmente integrado e com uma estrutura produtiva nos moldes da segunda Revolução Industrial. Porém, o elevado nível de endividamento das empresas e dos governos, o processo de estatização da dívida, os dois choques do petróleo (1973 e 1979) e a elevação unilateral da taxa de juros norte-americana em 1979 foram fatores que levaram à crise da dívida dos anos 1980 e ao esgotamento do modelo de industrialização por substituição de importações (ISI), conforme discutido por Carneiro (2002, p. 115-204) e Belluzzo e Almeida (2002, p. 93-272).

Desde os anos 1980, a economia brasileira encontra-se num ciclo de longo prazo de baixo nível de crescimento, redução da taxa de investimento e saída do Estado como agente coordenador do desenvolvimento. As articulações entre os aspectos macroeconômicos, microeconômicos e territoriais erigidos no modelo de ISI têm passado por um desmonte lento e gradual, que encontra nova fase na grande recessão do biênio 2015-2016. Nas décadas de 1980 e 1990, as empresas não-financeiras realizaram sucessivos ajustes defensivos, como estudado por Silva e Laplane (1994, p. 88), o que levou a uma redução do nível de investimento da economia, com impactos substanciais sobre a capacidade do investimento em liderar o crescimento de longo prazo.

Os anos 1980 são lembrados como a década perdida, em virtude do baixo crescimento do PIB, do PIB per capita, do ajustamento externo e do processo inflacionário. O ajustamento externo ocorreu às custas do sacrifício do mercado interno, via drive exportador, que beneficiou substancialmente setores industriais de bens intermediários e levou a um aumento da heterogeneidade setorial, como proposto por Carneiro (2002, p. 139-178). Os anos 1990, por sua vez, ficaram marcados pelas reformas neoliberais, com abertura comercial e financeira rápida e não planejada, privatizações, desnacionalização do parque industrial brasileiro, reforma gerencial do Estado e foram coroados pelo Plano Real ${ }^{3}$ que, apesar de mudanças na trajetória original, persiste até o momento atual (Tabela 1).

\footnotetext{
${ }^{3}$ Para um debate mais aprofundado sobre o Plano Real, ver Oliveira (2013, p. 127-206).
} 
Economia brasileira no início do século XXI: desaceleração, crise e desindustrialização (2000-2017)

Tabela 1. Política Econômica dos antecedentes até o período posterior ao Plano Real (1993-2016)

\begin{tabular}{|c|c|c|c|}
\hline \multirow{2}{*}{ Fases } & $\begin{array}{l}\text { Antecedentes } \\
(1993-1994)\end{array}$ & $\begin{array}{l}\text { Plano Real } \\
(1994-1998)\end{array}$ & $\begin{array}{l}\text { Tripé macroeconômico } \\
\text { (1999-2016) }\end{array}$ \\
\hline & $\begin{array}{c}\text { Fase preparatória: estratégia } \\
\text { gradualista }\end{array}$ & Âncora cambial & $\begin{array}{c}\text { Sistema de metas de } \\
\text { inflação }\end{array}$ \\
\hline \multirow{3}{*}{$\begin{array}{l}\text { Subperíodos } \\
\text { e seus ele- } \\
\text { mentos gerais }\end{array}$} & $\begin{array}{l}\text { Jun } 1993 \text { a Mar } 1994 \text { - } \\
\text { Programa de Ação Ime- } \\
\text { diata (PAI) }\end{array}$ & $\begin{array}{l}\text { Jul } 1994 \text { a } 1996 \text { - } \\
\text { Estabilidade monetária } \\
\text { com endividamento }\end{array}$ & $\begin{array}{l}\text { 1999-2006- } \\
\text { Nova estratégia: } \\
\text { i) Superávit Fiscal } \\
\text { ii) Taxa de câmbio flu- } \\
\text { tuante } \\
\text { iii) Metas de inflação }\end{array}$ \\
\hline & $\begin{array}{l}\text { Mar } 1994 \\
\text { a Jul } 1994- \\
\text { Unidade Real de Valor } \\
\text { (URV) }\end{array}$ & $\begin{array}{l}1997 \text { - Crise asiática: } \\
\text { aumento da vulnerabili- } \\
\text { dade externa e endivida- } \\
\text { mento interno }\end{array}$ & $\begin{array}{l}2007-2014 \text { - } \\
\text { Flexibilização limitada/ } \\
\text { Medidas macropruden- } \\
\text { ciais }\end{array}$ \\
\hline & $\begin{array}{l}1^{\circ} \text { Jul } 1994- \\
\text { Introdução da nova moe- } \\
\text { da (Real - R\$̣) }\end{array}$ & $\begin{array}{l}1998 \text { - Crise russa: mo- } \\
\text { vimentos defensivos e } \\
\text { mudança do regime fiscal }\end{array}$ & $\begin{array}{l}\text { 2015-atual - } \\
\text { Retomada das reformas } \\
\text { neoliberais }\end{array}$ \\
\hline
\end{tabular}

Fonte: elaboração própria a partir de Oliveira (2013) e Rossi, Dweck e Oliveira (2018).

Na avaliação de Belluzzo e Almeida (2002, p. 374), o Plano Real significava "(...) um projeto de desenvolvimento liberal que supõe a convergência relativamente rápida das estruturas produtivas e da produtividade da economia Grasileira na direção dos padrões 'competitivos' e 'modernos' das economias avançadas". Os impactos econômicos desse plano são assim sintetizados por Oliveira (2013, p. 181): "para manter a estabilidade de preços — praticamente o único triunfo do Plano Real - sacrificava-se o crescimento econômico e, para agravar o quadro, aumentava-se a vulnerabilidade externa da economia e a fragilidade fiscal do Estado brasileiro". O sentido geral das amplas reformas pelas quais o Brasil passou é explicitado por Cano (1996, p. 134-135):

(...) para 'completar' sua globalização nos países subdesenvolvidos, está causando um verdadeiro flagelo, sucateando precocemente capacidade produtiva e infraestrutura, ao exigir a moderna substituição daqueles ativos. Por outro lado, o debilitamento do Estado, que já era acentuado com a 'crise da dívida' aumentou ainda mais, com as políticas de ajuste neoliberais, desregulamentações, privatizações, exaustão da capacidade de planejamento e incapacitação da política econômica. A esses Estados nacionais pouco tem restado fazer para escapar de uma 'reação passiva'. Isso está agravando sobremodo a atual crise.

Os primeiros quinze anos do século XXI foram marcados por rupturas e descontinuidades nas trajetórias econômica, política e social. A recuperação do superávit 
comercial em 2001, em virtude da flutuação cambial de 1999, sinalizou um início de recuperação, porém de forma errática e inconsistente no tempo, e reforçou a ideia de voo de galinha. Após o medo Lula de 2002, a retomada da economia se manifestou de forma mais clara, principalmente após 2007, por condições internas e externas favoráveis até 2008, com a eclosão da crise financeira internacional, como discutido por Oliveira (2013, p. 263-388).

Entre os fatores externos para a recuperação do crescimento brasileiro no início do século XXI é possível destacar a retomada do crescimento mundial estimulado, principalmente, pelo efeito China ${ }^{4}$. Os impactos do aumento do nível de preços e quantidades exportadas das commodities agrícolas e mineiras melhoraram os termos de troca e isso beneficiou o Brasil com a aceleração do superávit comercial, o que representou certo alívio no financiamento no Balanço de Pagamentos, com sucessivos superávits em Transações Correntes, e contribuiu na retomada da acumulação interna. A contrapartida desse movimento, entre outros, foi o avanço da reprimarização da pauta exportadora, da desindustrialização precoce, portanto, do aprofundamento da dependência externa.

Em que pese a continuidade com o modelo do tripé entre 2003 e 2007, houve aumento da participação da relação crédito sobre PIB, política de valorização do salário mínimo, programas sociais e de inclusão, bem como tendência à redução da taxa de desemprego. Esses elementos levaram a uma queda da pobreza absoluta e do aumento da capacidade de gasto das famílias, sobretudo as de classes mais baixas, o que resultou numa nova rodada de modernização dos padrões de consumo.

A diversificação dos padrões de consumo sem correspondência na diversificação da estrutura de oferta, conjugadas com uma manutenção da economia aberta e uma burguesia com capacidade limitada de promover diversificação produtiva, levou a vazamentos de rendas e consequentes pressões sobre o setor externo e interno. Embora a melhoria do quadro social, do crescimento e da acumulação interna, o fosso do ponto de vista da demanda e da oferta, comparativamente às principais economias mundiais, persistissem elevados, conforme demonstram indicadores selecionados na Tabela 2.

Sinteticamente, Pinto e Gonçalves (2015, p. 470) definem o efeito China como "a contribuição relativa da China para a expansão do consumo mundial". 
Economia brasileira no início do século XXI: desaceleração, crise e desindustrialização (2000-2017)

Tabela 2. Posição do Brasil em indicadores econômicos e sociais selecionados

\begin{tabular}{|c|c|c|c|c|c|}
\hline $\begin{array}{l}\text { Contas Nacionais } \\
\text { (Deflator: PPC 2005) }\end{array}$ & $1995 n=204$ & $\begin{array}{c}2000 \\
n=204\end{array}$ & $\begin{array}{c}2005 \\
n=206\end{array}$ & $2010 n=208$ & $2014 n=212$ \\
\hline Produto Interno Bruto & 10 & 11 & 11 & 11 & 11 \\
\hline VA Manufatura & 9 & 11 & 13 & 13 & 13 \\
\hline PIB pc* & 80 & 85 & 88 & 89 & 92 \\
\hline Indicador Social & $1995 n=146$ & $\begin{array}{c}2000 \\
n=166\end{array}$ & $2005 n=181$ & $2010 n=188$ & $2014 n=188$ \\
\hline IDH & 69 & 67 & 77 & 80 & 75 \\
\hline Competitividade & $\begin{array}{c}2007-2008 \\
n=131\end{array}$ & $\begin{array}{c}2008-2009 \\
n=134\end{array}$ & $\begin{array}{c}2010-2011 \\
n=139\end{array}$ & $\begin{array}{c}2011-2012 \\
n=142\end{array}$ & $\begin{array}{c}2016-2017 \\
n=138\end{array}$ \\
\hline $\begin{array}{l}\text { Índice de Competitivi- } \\
\text { dade Global }\end{array}$ & 72 & 64 & 58 & 53 & 81 \\
\hline Inovação & $2013 n=142$ & $2014 n=143$ & $2015 n=141$ & $2016 n=128$ & - \\
\hline $\begin{array}{l}\text { Global Innovation } \\
\text { Index }\end{array}$ & 64 & 61 & 70 & 69 & - \\
\hline
\end{tabular}

Legenda: $\mathrm{n}$ = número de observações da amostra de cada ano para cada pesquisa

*inclui paraísos fiscais e países exportadores de petróleo

Fonte: elaboração própria com dados de UnctadStat, World Economic Fórum e Cornell University

Após navegar em "céu de brigadeiro", como nomeado por Oliveira (2013, p. 371), a economia brasileira sofreu com a eclosão da crise financeira internacional de 2008 e seus posteriores desdobramentos. Segundo Mészáros (2000, p. 14), trata-se de uma "crise estrutural do capital", onde o processo de globalização, em suas várias dimensões —entre elas, a econômica, social, política e ambiental—, encontra seus próprios limites, fato que pode encaminhar para uma guerra generalizada, inclusive com exacerbação dos nacionalismos. Sem melhoria no quadro externo, com desdobramentos da crise original, em 2011, o conjunto de políticas anticíclicas passa a ter efeitos menores sobre a demanda agregada, e aí inicia a desaceleração cíclica. Por fim, as reformas de corte neoliberal, sob o argumento da austeridade fiscal, com tendência à retirada de direitos sociais, retomaram com força após 2015 e continuaram até os dias atuais.

Após 2007, entre economistas, houve a retomada de debates sobre políticas desenvolvimentistas, com mais evidência do debate teórico entre as correntes social-desenvolvimentista e novo-desenvolvimentista. Já do ponto de vista 
da condição da política econômica, apesar de a flexibilização do modelo do tripé macroeconômico, a crise trouxe efeitos para o Brasil, como elucida Cruz (2010, p. 22):

a crise chega a nós por vários caminhos: i) pelo corte abrupto das linhas de crédito, que afetaram imediatamente as exportações; ii) pela queda nos preços de produtos importantes na pauta de exportação de nossos países; iii) pela queda acentuada no valor das remessas internacionais realizadas por trabalhadores migrantes — fator que afeta particularmente o México e países da América Central; iv) pela queda na arrecadação fiscal; v) pela redução no ritmo de implantação de projetos em curso e suspensão de investimentos planejados - por causa da escassez de crédito e, sobretudo, de grande incerteza que paira sobre os cenários macroeconômicos; vi) pela contração do consumo, em consequência do encolhimento do crédito e das incertezas das famílias quanto aos seus rendimentos a curto e médio prazos.

Avançou-se na concessão de crédito em concessões favoráveis para empresas privadas, via bancos públicos, financiamento imobiliário, aumento do gasto público em investimentos, avanço na concessão de empresas e serviços públicos, redução de impostos - por exemplo, para automóveis e linha branca—, e aumento de subsídios, os quais tiveram impactos na manutenção de certo dinamismo da economia, ainda que em bases frágeis e, principalmente do elevado nível de emprego. Segundo Carvalho (2018), a política de subsídios significou a implantação da agenda Fiesp, com elevado custo para o orçamento público. As flexibilizações do modelo, de um modo geral, diante da hecatombe financeira global, ficaram conhecidas como medidas macroprudenciais, conforme Goudart e Terra (2015, p. 180).

Nesse conjunto, as contas externas tiveram elevados déficits em transações correntes, aceleração das importações, aceleração do gasto com turismo no exterior e elevação do passivo externo líquido, o que aponta para aumento de nossa vulnerabilidade externa estrutural, segundo Gonçalves e Pinto (2016, p. 453), dada a aceleração da exportação de capitais. Por outro lado, houve aumento do endividamento público e privado, do governo, das empresas e das famílias, o que levou à hipótese de instabilidade financeira endógena, conforme Rezende (2016, p. 40).

Ao não enfrentar questões estruturais, as alternativas anticíclicas apresentaram esgotamento ao final de 2014. A opção pela retomada dos princípios das políticas do Consenso de Washington no Brasil —entre eles, o discurso da austeridade fiscal e dos não desprezíveis impactos da Operação Lava Jato-, pesou sobre a economia brasileira e levou a pífios resultados nos anos de 2015 e 2016 (Tabela 3), o que Romero (2017, p. 1) chamou de a "grande recessão". Entre as mais graves crises econômicas da história brasileira, os ganhos sociais foram desconstruídos e a indústria e o investimento definharam, num movimento de profundas reformas do Estado. Algumas já aprovadas — como a fiscal, via Proposta de Emenda Constitucional (PEC) 55, 
que inviabiliza a política fiscal_- e outras a caminho, tais como a previdenciária, a trabalhista e a tributária. Com sustentação política, o Governo Temer aplica a agenda da Ponte para o Futuro, o qual ainda não mostrou capacidade de recuperação econômica, porém, com tendência à retirada de direitos sociais, conforme estudos de Rossi, Dweck e Oliveira (2018).

Tabela 3. Produto Interno Bruto —Brasil— Taxa de variação média anual (em \% a.a.)

\begin{tabular}{lccccc}
\hline Agropecuária & 5,6 & 4,0 & 2,9 & 3,3 & 3,8 \\
\hline Indústria & 1,2 & 3,0 & 3,8 & 1,0 & $-3,3$ \\
\hline Indústrias extrativas & 6,1 & 4,3 & 4,8 & 1,8 & 2,4 \\
\hline Indústrias de transformação & 1,6 & 3,8 & 2,3 & $-0,5$ & $-4,2$ \\
\hline SIUP & 0,2 & 4,2 & 3,9 & 1,5 & 2,5 \\
\hline Construção & $-0,1$ & $-0,2$ & 8,5 & 3,4 & $-6,6$ \\
\hline Serviços & 2,7 & 3,5 & 4,6 & 2,5 & $-1,7$ \\
\hline PIB & 2,3 & 3,5 & 4,6 & 2,3 & $-2,0$ \\
\hline Consumo das famílias & 1,6 & 3,3 & 5,9 & 3,5 & $-2,2$ \\
\hline Consumo do governo & 2,0 & 2,8 & 3,2 & 1,7 & $-0,7$ \\
\hline FBCF & $-1,2$ & 3,2 & 9,8 & 2,2 & $-8,8$ \\
\hline Exportação & 8,5 & 9,9 & 2,0 & 1,6 & 4,6 \\
\hline Importação (-) & $-4,2$ & 8,6 & 14,6 & 3,7 & $-6,8$ \\
\hline
\end{tabular}

Fonte: IBGE/Contas Nacionais Trimestrais

Os dados da Tabela 3 apontam que as variáveis formação bruta de capital e fixo (FBCF) e indústria de transformação foram as mais afetadas a partir da segunda década do século XX, ou seja, a partir do ciclo da desaceleração. Com efeito, entre 2011 e 2017, a taxa acumulada na FBCF foi de -17,2 \% e, na indústria de transformação, $-14,0 \%$. Nessa mesma comparação, o consumo das famílias teve resultado de $7,5 \%$, o do governo $4,7 \%$, as exportações $21,9 \%$ e as importações $-6,8 \%$ - em geral, esses resultados estão relacionados com o bom desempenho entre 2011-2014. Ainda ao considerar o período 2011-2017, a agropecuária cresceu $27,4 \%$ e a indústria extrativa aumentou $15,0 \%$, o que tende a pressionar para inserção externa baseada em recursos naturais. Embora não se possa tratar esse período como tendência, já se configura como uma trajetória de médio prazo de difícil recuperação. 
Segundo os argumentos apresentados, é possível sugerir uma dinâmica cíclica que, não por acaso, segue os ciclos eleitorais da economia brasileira. Ou seja, podese falar de um início de retomada no período de 1999 a 2002, uma recuperação do crescimento no período de 2003 a 2006, uma posterior aceleração do crescimento, de 2007 a 2010, seguida, por sua vez, de uma desaceleração cíclica, entre 2011 e 2014, e, por fim, aguda crise, ou mesmo grande recessão que se apresenta, até o momento, no biênio 2015-2017. Em particular, na próxima seção pretende-se destacar as trajetórias do setor produtivo nesses ciclos e enfatizar a hipótese de desindustrialização absoluta na segunda década do presente século.

\section{DESINDUSTRIALIZAÇÃO NO BRASIL: AGRAVAMENTO NO QUADRO DE DESACELERAÇÃO E CRISE}

Segundo Furtado (1992, p. 32), a industrialização pode ser entendida como a articulação de um sistema econômico nacional, com formação dos centros internos de decisão, alavancada pelo mercado interno, principalmente via diversificação produtiva e integração intra e interdepartamental. Seguindo essa lógica, a desindustrialização pode ser compreendida como a desarticulação dos mecanismos que gestaram o processo de industrialização, com perdas de importância dos centros internos de decisão. Nas palavras do autor: "A atrofia dos mecanismos de comando dos sistemas econômicos nacionais não é outra coisa senão a prevalência de estruturas de decisões transnacionais, voltadas para a planetarização dos circuitos de decisões" (Furtado, 1992, p. 24).

Com a adoção das medidas de corte neoliberal, o Consenso de Washington, houve um processo de abertura comercial rápido e não planejado, acompanhado de privatizações e desnacionalizações do setor manufatureiro no Brasil. O capital estrangeiro aumentou seu peso na estrutura produtiva, via internacionalização, por fusões e aquisições ou por novos investimentos (greenfield), em geral, ao buscar o mercado interno, conforme Laplane, Coutinho e Hiratuka (2003, p. 11-58), e passou a conduzir a lógica de comando, em múltiplas dimensões, nos âmbitos público e privado. Esse fato elevou o poder de barganha do capital nacional nas decisões internas, com importância na determinação do papel do país no mercado mundial.

No bojo das transformações das grandes corporações transnacionais, com a formação das redes globais de produção, a grande empresa capitalista passou a acelerar seus processos de concentração e centralização do capital, sobretudo com seu entrelaçamento com o sistema financeiro e o mercado de capitais, como discutido por Vitali, Gattfelder e Battiston (2011, p. 7), com alta concentração geográfica, principalmente na América do Norte e na União Europeia, de acordo com 
Vitali e Battiston (2014, p. 5). Essas formas de fragmentação espacial da produção capitalista levaram a uma distribuição desigual entre a produção e apropriação de valor no globo, o que ampliou as assimetrias entre as nações.

No Brasil, ao enfrentar questões como a crise da dívida externa e a aceleração do processo inflacionário nos anos 1980, o debate sobre a estrutura produtiva ficou em segundo plano na agenda nacional. Contudo, a produção material avançou de forma acelerada, consoante os novos setores, processos de gestão, relações com o capital financeiro típicos da terceira revolução industrial, como apresentado por Coutinho (1992, p. 71-86). Na periferia capitalista tiveram destaque a inserção do sudeste asiático, especialmente Coreia do Sul, Taiwan e China, como discutido por Akyuz (2005, p. 45-48). A América Latina, em particular o Brasil, não obteve dinamismo. Ao contrário, passou por um lento, gradual e longo processo de desarticulação de sistema produtivo, com impactos sobre as possibilidades de crescimento no longo prazo, cujos efeitos são devastadores, principalmente no último biênio.

Cano (2017, p. 16) traz à tona a importância da manufatura para o desenvolvimento econômico. Segundo esse autor, é possível argumentar uma relação particular entre Estado-Desenvolvimento-Industrialização, na qual a manufatura (indústria de transformação) cobre as seguintes funções: transformação e multiplicação da utilidade de bens; condicionamento da alteração das bases do progresso técnico, com irradiação sobre agricultura e serviços; acentuação da urbanização e ampliação da demanda; alteração das pautas de exportação e alívio no financiamento do Balanço de Pagamentos; impactos sobre as estruturas de empregos, salários e organização sindical; necessidade de investimentos em infraestrutura de toda ordem; transformações políticas e econômicas dos Estados modernos, porém, com corrosiva dominação do capital financeiro no pós-1980.

Segundo Sampaio (2015, p. 84), a desindustrialização no Brasil, por uma perspectiva que segue a linha estruturalista de interpretação do desenvolvimento capitalista no Brasil, pode ser compreendida como relativa nas dimensões: i) elevação das assimetrias tecnológicas; ii) desarticulação de cadeias produtivas e iii) substituição da produção final nacional pela estrangeira. Essas formas pela qual a desindustrialização se manifestou na economia brasileira predominaram até o final da década de 2010. Elas são consideradas relativas porque são compatíveis com o crescimento industrial, ainda que a taxas baixas. Manifestam-se, portanto, na rearticulação de aspectos micro, macroeconômicos e territoriais, agora mais voltados para a interlocução direta com o exterior. Porém, com o avanço dos impactos da crise financeira internacional e da ausência de retomada do protagonismo industrial, a desindustrialização no Brasil está avançando sob sua forma mais grave: a desindustrialização absoluta. 
Na seção anterior foi destacado que no período após 2011, a FBCF e a indústria de transformação foram os setores do PIB mais afetados nos períodos de desaceleração e crise. Vejamos a situação mais de perto, primeiramente, ao fazer a observação da produção física industrial nos períodos selecionados.

Tabela 4. Taxa média de variação anual da produção física industrial brasileira por grandes categorias econômicas (em \% a.a.)

\begin{tabular}{lcccc}
\hline \multicolumn{1}{c}{ Grandes categorias econômicas } & $2003-2006$ & $2007-2010$ & $2011-2014$ & 2015-2017 \\
\hline Bens de capital & 7,6 & 8,8 & $-1,3$ & $-10,6$ \\
\hline Bens intermediários & 2,8 & 1,9 & $-0,9$ & $-3,4$ \\
\hline Bens de consumo & 3,8 & 2,8 & $-0,2$ & $-4,0$ \\
\hline Bens de consumo duráveis & 9,2 & 5,7 & $-2,4$ & $-7,6$ \\
\hline $\begin{array}{l}\text { Bens de consumo semiduráveis e não } \\
\text { duráveis }\end{array}$ & 2,5 & 1,9 & 0,5 & $-3,0$ \\
\hline
\end{tabular}

Fonte: IBGE/PIM-PF

Com efeito, a Tabela 4 mostra o desempenho por grandes categorias econômicas, cujos resultados indicam que somente os bens de consumo semiduráveis e não duráveis obtiveram certo crescimento no período de 2011 a 2014 (0,5 \% a.a.). Bens de capital, importante setor para a reprodução interna do capital, entre 2011 e 2016, têm taxa acumulada de queda de 32,1 \%, com maior impacto no último triênio (-10,6 \%). No mesmo período comparativo, bens de consumo duráveis têm resultado próximo, com queda acumulada de $28,3 \%$. Os resultados são expressivos, principalmente nos setores de maior complexidade econômica. Ao aproximar pela análise setorial, é possível perceber outros impactos diferenciados na manufatura, conforme a Tabela 5.

Tabela 5. Taxa média de variação anual da produção física industrial brasileira da indústria de transformação por seção da CNAE 2.0 (em \% a.a.)

\begin{tabular}{lcccc}
\hline \multicolumn{1}{c}{ Seções e atividades industriais (CNAE ) } & 2003-2006 & 2007-2010 & 2011-2014 & 2015-2017 \\
\hline Indústria geral & 3,5 & 2,8 & $-0,7$ & $-13,5$ \\
\hline Indústrias extrativas & 6,6 & 3,3 & 1,2 & $-4,5$ \\
\hline Indústrias de transformação & 3,3 & 2,8 & $-0,9$ & $-14,6$ \\
\hline Fabricação de produtos alimentícios & 1,2 & 1,5 & $-0,4$ & $-0,9$ \\
\hline Fabricação de bebidas & 3,7 & 5,9 & 0,1 & $-7,5$ \\
\hline Fabricação de produtos do fumo & 3,6 & $-5,5$ & $-2,9$ & $-24,4$ \\
\hline
\end{tabular}


Economia brasileira no início do século XXI: desaceleração, crise e desindustrialização (2000-2017)

\begin{tabular}{|c|c|c|c|c|}
\hline Seções e atividades industriais (CNAE) & $2003-2006$ & $2007-2010$ & 2011-2014 & $2015-2017$ \\
\hline Fabricação de produtos têxteis & 1,0 & $-1,1$ & $-7,0$ & $-17,4$ \\
\hline Confecção de artigos do vestuário e acessórios & $-4,5$ & 2,7 & $-4,0$ & $-15,9$ \\
\hline $\begin{array}{l}\text { Preparação de couros e fabricação de artefatos } \\
\text { de couro, artigos para viagem e calçados }\end{array}$ & $-3,4$ & $-2,9$ & $-3,6$ & $-8,7$ \\
\hline Fabricação de produtos de madeira & 0,3 & $-4,4$ & 1,8 & $-2,7$ \\
\hline $\begin{array}{l}\text { Fabricação de celulose, papel e produtos de } \\
\text { papel }\end{array}$ & 4,6 & 2,1 & 0,3 & 2,8 \\
\hline Impressão e reprodução de gravações & - & - & - & $-30,2$ \\
\hline $\begin{array}{l}\text { Fabricação de coque, de produtos derivados } \\
\text { do petróleo e de biocombustíveis }\end{array}$ & 0,8 & 0,9 & 3,5 & $-15,1$ \\
\hline $\begin{array}{l}\text { Fabricação de sabões, detergentes, produtos } \\
\text { de limpeza, cosméticos, produtos de perfuma- } \\
\text { ria e de higiene pessoal }\end{array}$ & 4,5 & 1,6 & 2,8 & $-4,2$ \\
\hline Fabricação de outros produtos químicos & 1,9 & 2,4 & 0,5 & $-7,0$ \\
\hline $\begin{array}{l}\text { Fabricação de produtos farmoquímicos e } \\
\text { farmacêuticos }\end{array}$ & 2,7 & 6,1 & 1,3 & $-15,5$ \\
\hline $\begin{array}{l}\text { Fabricação de produtos de borracha e de } \\
\text { material plástico }\end{array}$ & 1,2 & 2,5 & $-1,4$ & $-14,0$ \\
\hline $\begin{array}{l}\text { Fabricação de produtos de minerais não- } \\
\text { metálicos }\end{array}$ & 1,6 & 4,4 & 0,5 & $-18,2$ \\
\hline Metalurgia & 2,5 & 1,7 & $-3,0$ & $-12,6$ \\
\hline $\begin{array}{l}\text { Fabricação de produtos de metal, exceto } \\
\text { máquinas e equipamentos }\end{array}$ & 0,6 & 3,3 & $-3,0$ & $-21,2$ \\
\hline $\begin{array}{l}\text { Fabricação de equipamentos de informática, } \\
\text { produtos eletrônicos e ópticos }\end{array}$ & 11,5 & $-3,0$ & $-2,4$ & $-36,1$ \\
\hline $\begin{array}{l}\text { Fabricação de máquinas, aparelhos e materiais } \\
\text { elétricos }\end{array}$ & 6,8 & 3,5 & $-1,5$ & $-19,4$ \\
\hline Fabricação de máquinas e equipamentos & 5,5 & 5,4 & $-1,9$ & $-23,8$ \\
\hline $\begin{array}{l}\text { Fabricação de veículos automotores, reboques } \\
\text { e carrocerias }\end{array}$ & 9,8 & 7,7 & $-5,2$ & $-31,2$ \\
\hline $\begin{array}{l}\text { Fabricação de outros equipamentos de trans- } \\
\text { porte, exceto veículos automotores }\end{array}$ & 6,7 & 13,4 & 4,5 & $-29,7$ \\
\hline Fabricação de móveis & 0,6 & 2,1 & 0,3 & $-21,4$ \\
\hline Fabricação de produtos diversos & 3,4 & 0,9 & $-1,0$ & $-11,5$ \\
\hline $\begin{array}{l}\text { Manutenção, reparação e instalação de máqui- } \\
\text { nas e equipamentos }\end{array}$ & - & - & - & $-12,8$ \\
\hline
\end{tabular}

Fonte: IBGE/PIM-PF 
Por seção de atividade econômica (Tabela 5), os impactos sobre os setores mais complexos ficam mais claros, haja vista que reduções na produtividade física industrial entre 2011 e 2017 foram mais impactantes em: fabricação de veículos automotores $(-38,1 \%)$, fabricação de produtos têxteis (-35,8 \%), fabricação de equipamentos de informática ( $-34,4 \%)$, fabricação de produtos de metal $(-30,9 \%)$ e fabricação de máquinas e equipamentos (-28,0 \%). Entre 2011 e 2014, dos 23 setores, 14 tiveram uma taxa média de variação negativa, enquanto no triênio 2015-2017, dos 25 setores, somente um (celulose e papel) teve uma taxa média de variação positiva (2,8 \%). O quadro da destruição da produção física nacional mostra-se evidente e na trajetória de consolidação para um médio prazo. Para o estudo do Instituto de Estudos para o Desenvolvimento Industrial (IEDI) (2017, p. 1-4), o triênio 2014-2016 foi definido como devastador, uma vez que entre 96 segmentos industriais, oito deles tiveram quedas de produção física superior a 50 \%. Entre eles é possível destacar: ônibus e caminhões (-64\%), cabines, carrocerias e reboques (-66\%), equipamentos de informática e periféricos (-53\%) e outros bens de capital (-50\%).

O quadro de diminuição da produção interna pode ter relações com a substituição da produção nacional pela importada. Na seção anterior também foi discutido que a despeito da crise generalizada, o consumo das famílias apresentou desempenho melhor do que a indústria de transformação nos períodos de desaceleração e crise. Assim, parte do mercado doméstico passou a ser atendida diretamente pelas importações, principalmente nos setores de maior intensidade tecnológica (Gráfico 1).

Enquanto o coeficiente de penetração das importações (CPI) tem elevação a partir de 2005, principalmente após 2009, o nível de utilização da capacidade instalada (UCI) da indústria de transformação tem redução também após 2009, com acentuação de sua queda após 2014. A redução do CPI no último biênio é relevante, tendo em vista que demonstra uma mudança na trajetória que visa o ajuste externo, porém, ainda não recuperou os níveis do início da década (Gráfico 1).

O quadro da redução da importância do setor manufatureiro na economia brasileira também encontra respaldo nos dados de empregos e salários. O Gráfico 2 demonstra a queda absoluta do número de empregos no setor industrial a partir de 2013 e do salário média real em 2014. 
Economia brasileira no início do século XXI: desaceleração, crise e desindustrialização (2000-2017)

Gráfico 1. Utilização da capacidade instalada (UCI) - Coeficiente de penetração das importações (CPI) da indústria de transformação (em \%)

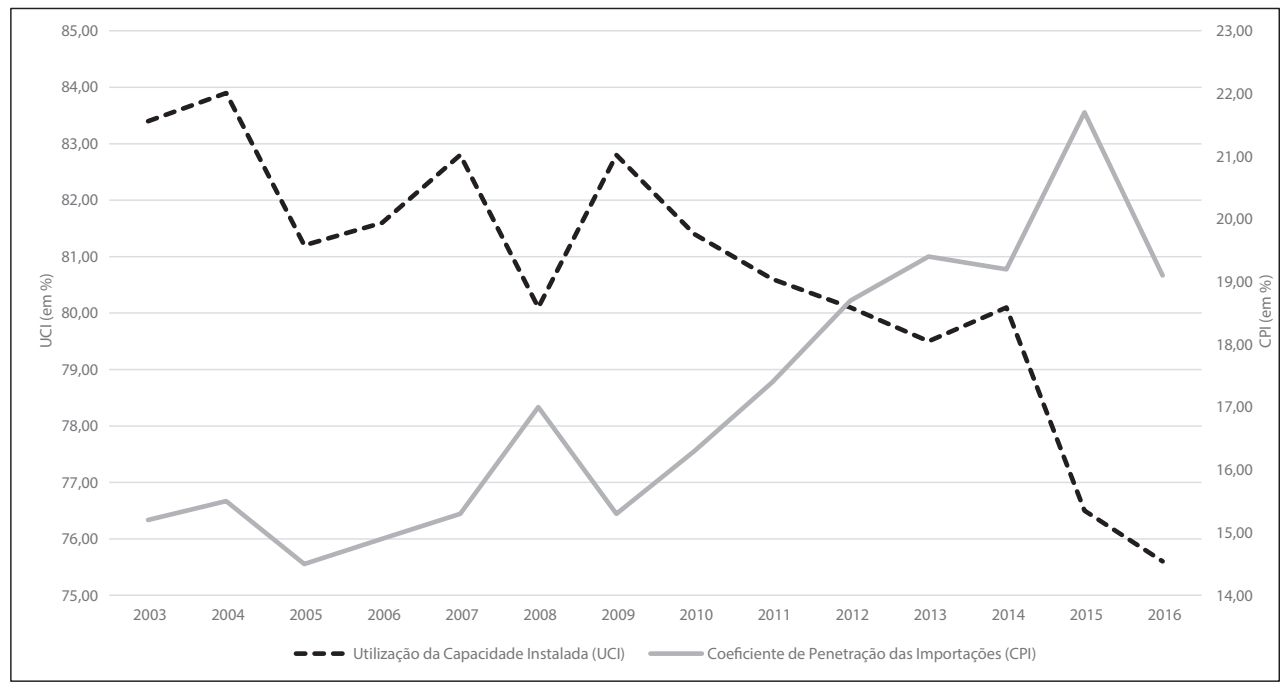

Fonte: $\mathrm{CNI}$

Gráfico 2. Total de empregados contratados e salário médio real na indústria de transformação no Brasil*

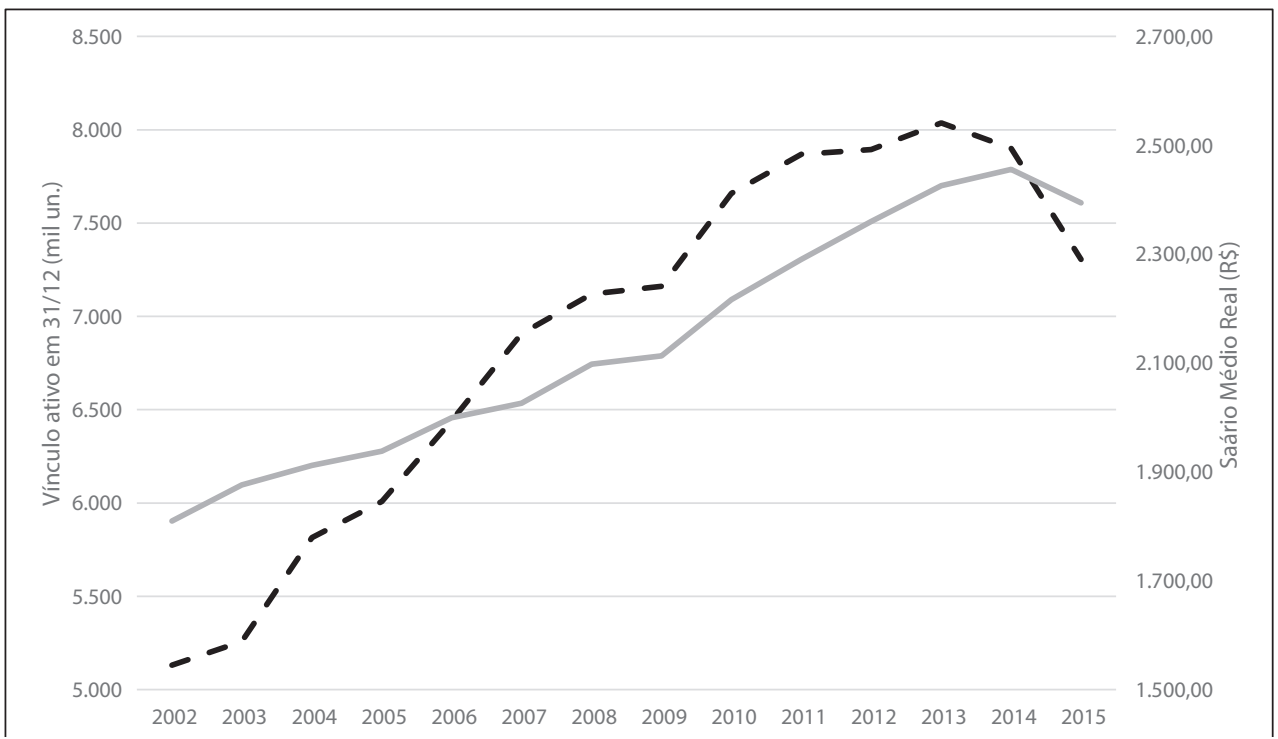

Número de vínculos ativos em 31 de dezembro em milhares por seção de atividade econômica (CNAE 95). Salário médio real deflacionado pelo IPCA (dez $2002=100)$.

Fonte: MTE/RAIS 
Com efeito, se desde 2002 observou-se crescimento do número de empregos na indústria de transformação, houve início de reversão das taxas de crescimento após 2010, o que resultou numa redução do número de empregados após 2013. Entre 2013 e 2015, a manufatura brasileira perdeu, de forma acumulada, 732.288 postos de trabalho e, entre 2014 e 2015, o salário médio real nesse setor reduziu-se em 2,5\%.

De acordo com os dados apresentados, percebe-se a gravidade do quadro pelo qual passa a indústria de transformação brasileira e isso revela o aprofundamento do subdesenvolvimento da economia brasileira - conforme argumentado por Cano (2014). A magnitude das variações tanto no médio prazo (2011-2017) quanto no curto prazo (2015-2017) é expressiva diante do quadro global e interno. A desindustrialização absoluta no Brasil poderá vir a se consolidar como fato estrutural caso a grande crise brasileira não se resolva. Porém, a atual condução da política econômica parece não se atentar para esse severo problema que agrava o quadro social brasileiro e sua inserção no mercado mundial.

\section{CONCLUSÕES}

Ao final do II Plano Nacional de Desenvolvimento (PND), a economia brasileira encontrava-se com parque industrial nos moldes da segunda Revolução Industrial, com integração de cadeias produtivas setoriais e regionais, além do fortalecimento dos centros internos de decisão. Depois de um longo processo de articulação do sistema produtivo nacional, que vigorou de 1930 a meados da década de 1980, a economia brasileira está passando por um longo processo de decadência do setor industrial, que mostra novas faces diante do movimento de desaceleração cíclica no início da segunda década do século XXI.

A crise da dívida e a aceleração do processo inflacionário colocaram limites para a continuação do processo de industrialização brasileiro. Com a mudança na agenda prioritária da política econômica e sucessivos ajustes defensivos, o investimento, a produção e a diversificação industrial arrefeceram em um contexto de profundas transformações globais. Essas transformações ocorreram com a mudança do padrão de acumulação capitalista, com a financeirização da riqueza global, da terceira revolução industrial, com o avanço da industrialização de países asiáticos, mudança na gestão, produção, distribuição e apropriação de valor da grande empresa capitalista.

A consolidação das reformas econômicas nos anos 1990, com abertura comercial e financeira, privatizações e desnacionalização da indústria contribuíram para o enfraquecimento dos centros internos e de decisão. Para além dessa questão, as 
amarras à política econômica colocadas pelo Plano Real coroaram as propostas do Consenso de Washington para a economia brasileira. Com o avanço da transnacionalização da estrutura produtiva brasileira, os centros de decisão mostraram-se mais voltados para o exterior, com impactos sobre as possibilidades da construção de um projeto nacional.

Condições mais favoráveis para o crescimento tiveram início somente após a flutuação cambial de 1999, em ciclos com periodicidades próximas aos ciclos eleitorais, posteriormente apresentaram uma retomada do crescimento (2003-2006), uma aceleração entre 2007-2010, com certa flexibilização do sistema de metas de inflação, a desaceleração de 2011-2014 e a grande recessão, que se manifestou no biênio 2015-2017.

Desde o processo de desaceleração da economia brasileira, no início da segunda década do século XXI, a formação bruta de capital físico e a indústria de transformação foram os mais afetados, com taxas médias anuais de crescimento negativas, de forma mais expressiva no último biênio. Os impactos setoriais foram diferenciados, porém de forma mais aguda nos bens de capital e nos bens de consumo duráveis, que são justamente os que agregaram maior incorporação de progresso técnico e encadeamentos departamentais. Os recuos foram mais agudos nos setores de equipamentos de informática, máquinas e equipamentos, veículos automotores, equipamentos de transportes, entre outros. Esses recuos sinalizam o aumento da heterogeneidade setorial, a dependência de importações e a elevação da capacidade ociosa instalada na indústria.

A redução do grau de industrialização no Brasil desde 1985 manifestou-se de forma predominante como uma desindustrialização relativa, na medida em que era compatível com crescimento econômico, ainda que a taxas baixas. Ela se manifestava ora como aumento das assimetrias tecnológicas, ora como desarticulação de cadeias produtivas, ora como substituição do produto final nacional pelo importado. A partir de 2011, com as expressivas reduções da capacidade de produzir, pode-se falar em uma trajetória que aponta para a forma mais grave da desindustrialização: a absoluta.

A regressão tecnológica da estrutura produtiva brasileira mostra-se evidente diante do quadro de redução da produção física industrial e de aumento da capacidade ociosa. Reforça, nesse sentido, a tendência à redução da diversificação da estrutura produtiva para setores de menor valor adicionado e de reprimarização da inserção externa brasileira. Esse movimento tem impactos substanciais na inserção brasileira no mercado mundial, e, principalmente, nas possibilidades de crescimento no longo prazo. 
De difícil reversão, o quadro atual da manufatura encontra-se agravado pela ausência de perspectivas de crescimento sustentado da demanda agregada nesta década. O subdesenvolvimento da economia brasileira aprofunda-se tanto pela ótica da demanda, com a reversão das melhorias sociais, quanto pela ótica da oferta, via aprofundamento do quadro da desindustrialização e reprimarização da inserção externa. Historicamente, a industrialização tem um papel relevante na determinação da inserção nacional no mercado mundial. Assim, cabe ao Brasil definir o papel que terá diante dos desafios e transformações do mercado global em grandes potências, com o governo Trump nos Estados Unidos.

\section{BIBLIOGRAFIA}

Akyuz, Yilmaz (2005). Impasses do desenvolvimento. Em: Novos Estudos, São Paulo, n.o 72, p. 41-56. http://dx.doi.org/10.1590/S0101-33002005000200003.

Belluzzo, Luiz G. De Mello e Almeida, Julio Gomes (2002). Depois da queda: a economia brasileira da crise da dívida aos impasses do Real. São Paulo: Ed. Civ. Brasileira, 412p.

Braga, Juan Carlos (1993). A financeirização da riqueza: a macroestrutura financeira e a nova dinâmica dos capitalismos centrais. Em: Economia e Sociedade, vol. 2, n. ${ }^{\circ}$ 1, p. 25-57

Cano, Wilson (1996). Notas sobre o imperialismo hoje. Em: Crítica marxista, n. ${ }^{\circ}$ 3, p. 132-135.

Cano, Wilson (2014). (Des)industrialização e (Sub)desenvolvimento. Em: Cadernos do Desenvolvimento, Rio de Janeiro, vol. 9, n. ${ }^{\circ}$ 15, p. 139-174.

Cano, Wilson (2017). Prefácio. Em: Monteiro Neto, Aristides.; Castro, Cesar Nunes e Brandão, Carlos Antonio. Desenvolvimento regional no Brasil: políticas, estratégias e perspectivas. Rio de Janeiro: Ed. Ipea, p. 11-19.

Carneiro, Ricardo (2002). Desenvolvimento em crise: a economia brasileira no último quarto do século XX. São Paulo: Ed. Unesp, 423p.

Carneiro, Flávio Lyrio (2017). Fragmentação internacional da produção e cadeias globais de valor. Em: Oliveira, Ivan Tiago Machado.; Carneiro, Flávio Lyrio e Silva, Edison Benedito. Cadeias Globais de Valor, Políticas Públicas e Desenvolvimento. Brasília: Ed. Ipea, p. 87-120.

Cário, Silvio Antonio Ferraz (Coord.) (2012). Processo de desindustrialização em Santa Catarina. Santa Catarina: Fiesc/UFSC/Neitec, 35p.

Carvalho, Laura (2018). A valsa brasileira: do boom ao caos econômico. São Paulo: Ed. Todavia, 2018, 189p.

Coutinho, Luciano (1992). A terceira revolução industrial e tecnológica: as grandes tendências de mudanças. Em: Economia e Sociedade, vol. 1, n. ${ }^{\circ}$ 1, p. 69-87.

Cruz, Sebastião (2010). Trajetórias, casos nacionais de reformas econômicas e respostas à crise mundial. Em: Texto para discussão CepalL-IPEA, n. ${ }^{\circ}$ 9. DF: Cepal/IPEA, 26p.

Ferreira, Josué Catharino (2015). Aspectos históricos e geográficos da industrialização de Santo André. Em: Anais do XI Congresso Brasileiro de História Econômica e $12^{\mathrm{a}}$ Conferência Internacional de História de Empresas, Vitória/ES, set. 2015, 30p. 
Furtado, Celso (1992). Brasil: a construção interrompida. Rio de Janeiro: Paz e Terra, 87p.

Furtado, Celso. (2007). Formação Econômica do Brasil. Rio de Janeiro: Civilização Brasileira, 341p.

Goudart, Gustavo Chagas e Terra, Fabio Henrique Bittes (2015). Política macroprudencial: uma leitura keynesiana. Em: Análise Econômica, Porto Alegre, n. 63, p. 171-190.

IEDI — Instituto de Estudos para o Desenvolvimento Industrial— (2017). Um triênio devastador (2014-2016). São Paulo: IEDI, 5p.

Laplane, Mariano; Coutinho, Luciano e Hiratuka, Célio (Org.) (2003). Internacionalização e desenvolvimento da indústria no Brasil. São Paulo: Unesp, 349p.

Mello, Juan Manuel (1982). O capitalismo tardio. São Paulo: Brasiliense, 182p.

Mészáros, István (2000). A crise estrutural do capital. Em: Outubro, vol. 2, n. 4, p. 7-15.

Oliveira, Fabricio Augusto (2013). Política econômica, estagnação e crise mundial (1980-2010). Rio de Janeiro: Azougue Editorial, 391p.

Paulani, Leda María (1999). Neoliberalismo e individualismo. Em: Economia e Sociedade, Campinas, vol. 8, n. ${ }^{\circ}$ 2, p. 115-127.

Pinto, Eduardo Costa e Gonçalves, Reinaldo (2015). Globalização e poder efetivo: transformações globais sob efeito da ascensão chinesa. Em: Economia e Sociedade, vol. 24, n. ${ }^{\circ}$ 2, 54, p. 449-479.

Rezende, Felipe (2016). Financial fragility, instability and the Brazilian crisis: a KeynesMinky-Godley approach. Em: Minds Discussion Paper, n. ${ }^{\circ}$ 1, 75p.

Romero, Cristiano (2017). PIB: a tragédia consumada. Em: Valor Econômico, 08 de março de 2017.

Rossi, Pedro; Dweck, Esther e Oliveira, Ana Luiza Matos (Org.) (2018). Economia para poucos: impactos da austeridade e alternativas para o Brasil. São Paulo: Autonomia Literária, 2018, $375 p$.

Rowthorn, Robert e Coutts, Ken (2004). De-industrialization and the balance of payments in advanced economies. Em: Cambridge Journal of Economics, vol. 28, n. ${ }^{\circ}$ 5, p. 767-790.

Sampaio, Daniel (2015). Desindustrialização e estruturas produtivas regionais no Brasil. Tese de Doutorado do Instituto de Economia da Unicamp, 234p.

Silva, Robson Dias (2009). Estrutura industrial e desenvolvimento regional no estado do Rio de Janeiro (1990-2008). Tese de Doutorado do Instituto de Economia da Unicamp, 231p.

Silva, Ana Lucia G. e Laplane, Mario Francisco (1994). Dinâmica recente da indústria brasileira e desenvolvimento competitivo. Em: Economia e Sociedade, vol. 3, n. ${ }^{\circ}$ 1, p. 81-98.

Singh, Ajit (1977). UK industry and the world economy: a case of de-industrialization? Em: Cambridge Journal of Economics, vol. 1, n. ${ }^{\circ}$ 2, p. 113-136.

Tregenna, Fionna (2009). Characterising deindustrialization: an analysis of changes in manufacturing employment and output internationally. Em: Cambridge Journal of Economics, vol. 33, n. ${ }^{\circ}$ 3, p. 433-466. 
Vitali, Stefanía e Battiston, Stefano (2014). The Community structure of the global network control. Em: PLoS One, vol. 9, n. ${ }^{\circ}$ 8, p. 1-13.

Vitali, Stefanía; Glattfelder, James e Battiston, Stefano (2011). The network of global corporate control. Em: PLos One, vol. 6, n. ${ }^{\circ}$ 10, p. 1-6.

Unctad —United Nations for Trade and Development — (2003). Trade and development Report. Genebra: Unctad, 184p. 